\title{
Antifungal Activity of Linear and Disulfide-Cyclized Ultrashort Cationic Lipopeptides Alone and in Combination with Fluconazole Against Vulvovaginal Candida spp.
}

Paulina Czechowicz ( $\square$ paulina.czechowicz.umedwroc@gmail.com )

Wrocław Medical University

Damian Neubauer

Medical University of Gdańsk

Joanna Nowicka

Wrocław Medical University

Wojciech Kamysz

Medical University of Gdańsk

Grażyna Gościniak

Wrocław Medical University

\section{Research Article}

Keywords: Candida, biofilm, vulvovaginal candidiasis, antifungal, lipopeptides, synergy, cationic lipopeptides, cyclic lipopeptides, disulfide cyclization

Posted Date: April 21st, 2021

DOl: https://doi.org/10.21203/rs.3.rs-440442/v1

License: (c) (i) This work is licensed under a Creative Commons Attribution 4.0 International License.

Read Full License 


\section{Abstract}

Vulvovaginal candidiasis (VVC) occurs in over $75 \%$ of women at least once during their lifetime and is an infection that significantly affects their health. Candida strains resistant to standard azole antifungal therapy and relapses of VVC are more and more common. Hypothetically, biofilm is one of the main reasons of relapses and failure of the therapy. Ultrashort cationic lipopeptides (USCLs) exhibit high antimicrobial activities. Our previous study on USCLs revealed that disulfide cyclization can result in selective antifungal compounds. Therefore, four USCL were selected and their antifungal activity were studied on 62 clinical strains isolated from VVC. The results showed that cyclic analogs have increased selectivity between fungal cells and keratinocytes and improved anticandidal activity than their linear analogs against both planktonic and biofilm cultures. On the other hand, linear lipopeptides in combination with fluconazole showed the synergistic effect. It was found that the minimum inhibitory concentrations of the tested compounds in combination with fluconazole were at least four times lower than when used separately. Our results indicate that combination therapy of VVC with USCLs and fluconazole at low non-toxic concentrations can be beneficial owing to the synergistic effect. However, further in vivo studies are needed to confirm this hypothesis.

\section{Introduction}

Vulvovaginal candidiasis (VVC) is the second most common type of vaginal infection, significantly reducing the quality and comfort of women's lives. According to estimates, more than $75 \%$ of women in childbearing age worldwide will experience a symptomatic episode of VVC at least once during their lifetime. Undoubtedly, this infection is of significant importance for women's health and represents a major challenge that modern medicine should be able to deal with. Meanwhile, it is often underestimated, while conventional treatments often result in therapeutic failure and/or recurrence of the infection ${ }^{1-6}$. Typical recurrent VVC (RVVC), defined as four or more episodes per year, affects at least $10 \%$ of patients. At the same time, Candida can colonize the vagina and about $1 / 5$ of women are asymptomatic carriers $1,2,4,5$. As the detailed pathomechanism of vaginal mucosa invasion by yeast-like fungi remains unclear, the prevention and treatment of the infection is significantly hampered ${ }^{2,3,7}$. Candida albicans remains the most common etiological factor of VVC, but for many years an increasing percentage of NCAC (NonCandida albicans Candida) fungi has been observed among vaginal isolates, such as Candida glabrata, Candida parapsilosis or Candida lusitaniae ${ }^{5,8-10}$. Many researchers are inclined to the hypothesis that the ability to form a highly resistant biofilm structure by these strains is one of the causes of therapy failure in $\mathrm{VVC}$ 2,3,5,7,8,10,11. At the same time, there is also an increase in the percentage of yeast-like fungi, especially among the NCAC group, resistant to the available antifungal drugs $1,2,4,5$. Therefore, the great amount of effort that has been put into the research on new antifungal therapies, including those against biofilm, is not surprising.

One of the promising classes of compounds are lipopeptides ${ }^{12-15}$. In general, lipopeptides consist of a peptide fragment and conjugated lipid residue(s). Lipopeptides can be divided into subclasses, of which 
ultrashort cationic lipopeptides (USCLs) are among the most effective against fungal strains. These compounds consist of a peptide with at most 7 amino acid residues with a net positive charge owing to the occurrence of basic amino acids such as arginine or lysine. The most common hydrophobic fragment of USCLS is a fatty acid chain. In effect, USCLs are amphiphilic and can easily interact with the negatively charged pathogen membrane. In the case of fungi, lipopeptides interact with negatively charged residues of sialic acid and phosphatidylinositol found in the cell membrane of these microorganisms ${ }^{16,17}$. Their mode of action is based on the permeabilization of the membrane bilayers, what leads to cell death ${ }^{13-15,18}$. They can exhibit plenty of biological properties, such as antibacterial, antifungal, antibiofilm, antiadhesive, anticancer and surface activities ${ }^{19}$. On the other hand, USCLs can be noticeably lytic to erythrocytes and cytotoxic to normal human cells ${ }^{13,15,18}$. One of the well-studied USCL with a proven antimicrobial activity is $\mathrm{C}_{16}-\mathrm{KKKK}^{-} \mathrm{NH}_{2}\left(\mathrm{C}_{16}\right.$ - palmitic acid) that contains four Llysine ( $\mathrm{K}$ - L-lysine) residues ${ }^{20-24}$. Our previous study on this lipopeptide and its analogs revealed that the substitution of L-lysine by L-arginine residue and disulfide-cyclization can result in compounds with improved antimicrobial activity and selectivity between Candida strains and human cells ${ }^{13}$. Based on our previous results, four lipopeptides with the most favorable antifungal properties were selected for further study $-\mathrm{C}_{16}-\mathrm{KKKK}^{-\mathrm{NH}_{2}}, \mathrm{C}_{16}-\mathrm{KRKK}^{-\mathrm{NH}_{2}}, \mathrm{C}_{16}-\mathrm{CKKKKC}^{-} \mathrm{NH}_{2}$, and $\mathrm{C}_{16}-\mathrm{CKRKKC}^{-\mathrm{NH}_{2}}$. The lipopeptides with cysteine residues were cyclized through intramolecular disulfide bridge formation ${ }^{13}$. Undoubtedly, compounds with different mode of action can potentiate each other's antifungal activity. It was found that a combination of some lipopeptides (e.g. surfactin) with common antifungal drugs (e.g. azoles) can result in a synergistic effect ${ }^{25-33}$.

In the context of fungal infections, interactions between conventionally used fluconazole and various AMPs are being investigated more and more frequently $27,34-39$. The literature includes several studies on the impact of cationic ultrashort lipopeptides on fungi, including for example dermatophytes, but to the best of our knowledge none of these reports concerned isolates from VVC ${ }^{40}$.

The aim of the study was to determine the antifungal activity of two linear lipopeptides: $\mathrm{C}_{16}-\mathrm{KKKK} \mathrm{NH}_{2}$ (L1), $\mathrm{C}_{16}-\mathrm{KRKK}^{-\mathrm{NH}_{2}}$ (L2) and their two cyclic analogs: $\mathrm{C}_{16}-{\mathrm{CKKKKC}-\mathrm{NH}_{2}}_{2}$ (C1) and $\mathrm{C}_{16}-\mathrm{CKRKKC}^{-\mathrm{NH}_{2}}$ (C2) against 62 clinical strains of various species of Candida isolated from vulvovaginal candidiasis, both in planktonic and biofilm form. Moreover, studies on the potential synergistic or additive effects of combinations of fluconazole with these compounds have been carried out.

\section{Results}

\section{Minimum inhibitory concentration}

Fluconazole and four tested lipopeptides exhibited antimicrobial activity against planktonic cultures of all Candida strains. 
The most common MIC of fluconazole was $\leq 0.125 \mu \mathrm{g} / \mathrm{mL}$ and was determined for $77 \%$ of the strains (48/62). All of them were $C$. albicans and only single strains of this species demonstrated a slightly higher MIC, not exceeding $2 \mu \mathrm{g} / \mathrm{mL}$. One isolate (C. Iusitaniae) was resistant to fluconazole (MIC = 64 $\mu \mathrm{g} / \mathrm{mL}$ ). The remaining NCAC strains exhibited minimum inhibitory concentrations of tested azole of 4 $\mu \mathrm{g} / \mathrm{mL}$ (all five $C$. glabrata isolates) or less. The distribution of MIC values of fluconazole is presented below in Fig. 1A.

Minimum inhibitory concentrations of lipopeptide $\mathrm{L} 1$ were in the range $2-64 \mu \mathrm{g} / \mathrm{mL}$, with $32 \mu \mathrm{g} / \mathrm{mL}$ as the most common value $(26 / 62, \approx 42 \%)$. No significant differences among various Candida species were observed. The cyclic analog of this lipopeptide (C1) exhibited MIC distribution in the lower concentration range between 1 and $32 \mu \mathrm{g} / \mathrm{mL}$. For almost half $(30 / 62, \approx 48 \%)$ of the tested strains, MIC of C1 was 4 $\mu \mathrm{g} / \mathrm{mL}$ and for 26 isolates $(\approx 42 \%)$ it was twice as high-8 $\mu \mathrm{g} / \mathrm{mL}$. No deviations in MICs were observed between different Candida species. MIC distribution for $\mathrm{L} 1$ and $\mathrm{C} 1$ is presented below in Fig. 1B.

The second pair of lipopeptides, the one with arginine residue, exhibited less pronounced differences in MIC distribution. MIC concentration range for $L 2$ was $1-32 \mu \mathrm{g} / \mathrm{mL}$, while for $C 2$ it was $1-16 \mu \mathrm{g} / \mathrm{mL}$. For nearly $50 \%(29 / 62, \approx 47 \%)$ of strains, minimum inhibitory concentrations of linear lipopeptides were 16 $\mu \mathrm{g} / \mathrm{mL}$, followed by $32 \mu \mathrm{g} / \mathrm{mL}(20 / 62, \approx 32 \%)$. The most frequent concentration of the cyclic compound was $4 \mu \mathrm{g} / \mathrm{mL}(32 / 62, \approx 52 \%)$. As with the first pair of lipopeptides, no difference in MIC distribution was observed for individual Candida species. MIC distribution of L2 and C2 lipopeptides is displayed in Fig. 1C.

To evaluate lipopeptides selectivity, the results of our previous study on cytotoxicity against $\mathrm{HaCaT}$ cell line (immortalized human keratinocytes) were included ${ }^{13}$. Geometric mean (GM) MIC values were calculated. Selectivity indices $(\mathrm{SI})$ were calculated as the ratio of $\mathrm{IC}_{50}$ to $\mathrm{GM}$. The results are presented in Table 1.

Table 1

Geometric mean of MICs (GM_MIC), IC $50_{0}$ and selectivity indices (SI) of four tested lipopeptides.

\begin{tabular}{|llll|}
\hline Lipopeptide & GM_MIC $[\mu \mathrm{g} / \mathrm{mL}]$ & $\begin{array}{l}\mathrm{IC}_{50} \\
\text { (Neubauer et al. 2020) }\end{array}$ & SI \\
\hline L1 & 26.46 & $23.5 \pm 1.3$ & 0.89 \\
\hline C1 & 4.89 & $26.9 \pm 1.9$ & 5.50 \\
\hline L2 & 15.47 & $4.3 \pm 0.9$ & 0.28 \\
\hline C2 & 3.83 & $33.8 \pm 3.1$ & 8.83 \\
\hline
\end{tabular}

Minimum biofilm eradication concentration 
Fungistatic fluconazole failed to eradicate the biofilm of Candida strains. For almost all strains $(58 / 62, \approx$ $94 \%)$ MBEC values were extremely high $(512 \mu \mathrm{g} / \mathrm{mL})$ and for the remaining isolates eradication concentrations were even higher. The distribution of MBECs are presented below in Fig. 2A.

In contrast to fluconazole, all four lipopeptides have proved to be effective in biofilm eradication. In the case of the first pair of lipopeptides L1 and C1 (consisting of lysine residues only), similarly to MICs, the obtained MBECs were significantly lower for cyclic lipopeptide than for the linear analog. The most common MBEC value for $\mathrm{L} 1$ was $256 \mu \mathrm{g} / \mathrm{mL}(25 / 62, \approx 40 \%)$, followed by $128 \mu \mathrm{g} / \mathrm{mL}(16 / 62, \approx 26 \%)$ and concentration above $256 \mu \mathrm{g} / \mathrm{mL}(17 / 62, \approx 27 \%)$. On the other hand, for the vast majority of strains $(41 / 62, \approx 66 \%)$ minimum biofilm eradication concentrations of the second lipopeptide (C2) were 64 $\mu \mathrm{g} / \mathrm{mL}$. Again, no differences in MBECs were observed in term of species. The results of MBEC value determination are shown in Fig. 2B.

The MBECs of lipopeptides L2 and C2 were very similar to those described above. In the case of cyclic lipopeptide, MBEC value of $64 \mu \mathrm{g} / \mathrm{mL}$ was definitely dominant $(47 / 62, \approx 76 \%)$. For the linear parent molecule, the values were more distributed. The most common MBEC was $256 \mu \mathrm{g} / \mathrm{mL}(30 / 62, \approx 48 \%)$ followed by $128 \mu \mathrm{g} / \mathrm{mL}(16 / 62, \approx 26 \%)$ and $>256 \mu \mathrm{g} / \mathrm{mL}(12 / 62, \approx 19 \%)$. No differences for $C$. albicans versus NCAC fungi were observed. The results are presented below in Fig. $2 \mathrm{C}$.

Geometric means of MBECs were calculated. If MBEC was above $256 \mu \mathrm{g} / \mathrm{mL}$ then $512 \mu \mathrm{g} / \mathrm{mL}$ was taken into calculations as the next theoretical concentration in the serial dilution method, but $1024 \mu \mathrm{g} / \mathrm{mL}$ was used if MBEC of fluconazole was above $512 \mu \mathrm{g} / \mathrm{mL}$. Importantly, although this mathematical operation includes resistant strains in the calculations, their precise effective concentrations are not known. The calculated GM_MBECs of linear lipopeptides were congruent. In the case of $L 1$ it was $236.73 \mu \mathrm{g} / \mathrm{mL}$ and $223.86 \mu \mathrm{g} / \mathrm{mL}$ for the L2 lipopeptide. The calculated GM_MBECs of cyclic analogs were similar. GM_MBEC of lipopeptide with an arginine residue (C2) was $65.45 \mu \mathrm{g} / \mathrm{mL}$ and $56.59 \mu \mathrm{g} / \mathrm{mL}$ for C1.

\section{Fractional inhibitory concentration index (FICi)}

To initially asses the interaction of each fluconazole-lipopeptide combination, 24 of the tested strains were randomly selected of which 15 isolates were $C$. albicans and the remaining 9 were from the NCAC group. The interpretation of FIC indices was as follows: $\mathrm{FICi} \leq 0.5$ indicates synergy (SYN), $>0.5$ to $\leq 1.0$ addition (ADD), $>1.0$ to $\leq 2.0$ means indifference (IND) and $\mathrm{FICi}>2.0$ means antagonism (ANT) ${ }^{41}$. The results are collected in Fig. 3.

Although no synergy was observed among the tested fluconazole-lipopeptide pairs against Candida strains, an additive effect was determined, especially in the case of $C$. albicans isolates. The distribution of the results on the histograms (Fig. 3) clearly indicates that the additive effect is more frequent for both linear lipopeptides combined with fluconazole: L1 $(15 / 24, \approx 63 \%)$ and L2 $(11 / 24, \approx 46 \%)$. For cyclic analogs combined with fluconazole, the dominant result was indifference: $\approx 71 \%(17 / 24)$ for $\mathbf{C} 1$ and $\approx$ $58 \%$ (14/24) for C2. A simultaneous use of cyclic USCLs with fluconazole has an antagonistic or neutral effect against strains of the NCAC group, e.g. C. glabrata and $C$. kefyr, in contrast to their linear 
counterparts. The FIC index determined for $C$. albicans isolates was in agreement with the overall results, with an additive effect obtained mostly for linear lipopeptides.

As preliminary research on the FIC index was carried out on a small number of strains, it was decided to conduct the rest of the study with a pair of linear and cyclic analogs in order to investigate the interactions of USCLs with different structures more precisely. Based on the obtained results, two lipopeptides were selected for further experiments: linear L1 and its cyclic analog C1. Both USCLs showed more favorable effects (Fig. 3, additive effect) against Candida in combination with fluconazole than lipopeptides with arginine residue.

The FIC indices of combinations of fluconazole-L1 and fluconazole-C1 were determined against the remaining 40 isolates. The results (64 isolates, reference strains included) are shown in Figs. 4 and 5.

In the case of the linear lipopeptide, the results obtained for all 64 strains were consistent with those described for 24 isolates (Fig. 3). Altogether, an additive effect with fluconazole was dominant $(54 / 64, \approx$ $84 \%)$. A similar result was observed for $C$. albicans strains $(48 / 53, \approx 91 \%)$. Among NCAC fungi, additive effect was the most frequent as well $(6 / 11, \approx 55 \%)$, but it is difficult to draw strict conclusions due to a relatively small pool of strains. At first, cyclic $\mathbf{C 2}$ seemed to have an indifferent effect in combination with the tested azole but a study on 64 strains revealed that addition is the most common result $(34 / 64, \approx$ $53 \%$ ) in reference to all Candida species and also in the case of $C$. albicans species. Unfortunately, this pair of USCL-fluconazole had still a predominantly neutral effect against NCAC group $(7 / 11, \approx 64 \%)$.

Interestingly, the FIC index itself is an arithmetic mean of 8 obtained individual FIC values. When searching for the most advantageous combination of fluconazole-lipopeptide concentrations, it is the single FIC values (and the corresponding concentrations) that should be taken into account and interpreted. For the vast majority of strains and both USCLs-azole pairs, a synergistic effect could be observed (FIC $\leq 0.5)$. This applies in particular to the linear lipopeptide L1. An analysis of the most beneficial (the lowest possible) FIC values of fluconazole-L1 showed that synergy between these two compounds is achieved against $\approx 72 \%(46 / 64)$ of the strains. Consistent results were obtained for $C$. albicans isolates (synergistic effect against $40 / 53, \approx 75 \%$ of strains). Synergy was also the most common among NCAC fungi $(6 / 11, \approx 55 \%)$. In the case of cyclic USCL, synergistic effect occurred less often when single FIC values were analyzed, with the additive effect being dominant. For the fluconazoleC1 combination, synergism was present in $\approx 23 \%(15 / 64)$ of cases, including in $\approx 26 \%(14 / 53)$ concerned $C$. albicans and only $\approx 10 \%(1 / 11)$ NCAC. At the same time, additive effect was achieved in $\approx$ $61 \%(39 / 64)-\approx 62 \%$ for $C$. albicans and in $\approx 55 \%(6 / 11)$ of the remaining strains. Lipopeptide concentrations corresponding to FIC values indicating synergy were at least 4 times lower than MICs obtained for these strains. For example, when MIC value of L1 was $64 \mu \mathrm{g} / \mathrm{mL}$, synergistic effect was observed when a combination of $8 \mu \mathrm{g} / \mathrm{mL}$ of lipopeptide and $0.031 \mu \mathrm{g} / \mathrm{mL}$ of fluconazole was used. The concentrations of the discussed fluconazole-L1 pair corresponding to synergistic effect, compared to the obtained MIC values, are shown in Table 2. The corresponding data for the fluconazole-C1 combination was included in the supplementary material. 
Table 2

Concentrations of fluconazole-L1 combination exhibited a synergistic effect against 46 isolates of Candida strains.

\begin{tabular}{|c|c|c|c|}
\hline & FIC & & \\
\hline $\begin{array}{l}\text { MIC of } \\
\text { L1 } \\
{[\mu \mathrm{g} / \mathrm{mL}]}\end{array}$ & $\begin{array}{l}\text { L1 } \\
{[\mu \mathrm{g} / \mathrm{mL}]}\end{array}$ & $\begin{array}{l}\text { Fluconazole } \\
{[\mu \mathrm{g} / \mathrm{mL}]} \\
\text { (random order) }\end{array}$ & $\begin{array}{l}\text { No. of strains against which this combination was } \\
\text { effective }\end{array}$ \\
\hline 16 & 2 & 0.002 or 0.5 & $\begin{array}{l}2 \times \text { C. albicans } \\
1 \times \text { C. glabrata }\end{array}$ \\
\hline 16 & 4 & $\begin{array}{l}0.002 \text { or } 0.031 \text { or } \\
0.5\end{array}$ & $5 \times$ C. albicans \\
\hline 32 & 8 & 0.002 or 0.031 & $8 \times$ C. albicans \\
\hline 32 & 4 & $\begin{array}{l}0.002 \text { or } 0.004 \text { or } \\
0.5\end{array}$ & $\begin{array}{l}6 \times \text { C. albicans } \\
1 \times \text { C. glabrata }\end{array}$ \\
\hline 32 & 2 & 0.002 or 0.063 or 1 & $\begin{array}{l}5 \times \text { C. albicans } \\
3 \times \text { C. glabrata }\end{array}$ \\
\hline 64 & 16 & 0.002 or 0.016 & $3 \times$ C. albicans \\
\hline 64 & 8 & 0.002 or 0.031 & $6 \times$ C. albicans \\
\hline 64 & 4 & 0.002 or 0.004 & $4 \times$ C. albicans \\
\hline 64 & 2 & 0.004 or 1 & $\begin{array}{l}1 \times \text { C. albicans } \\
1 \times \text { C. Iusitaniae }\end{array}$ \\
\hline
\end{tabular}

\section{Discussion}

Being a local infection not associated with mortality, vulvovaginal candidiasis (VVC) is a clinical problem that is relatively often underestimated in comparison to other types of infections, including other candidosis. Meanwhile, it is a common disease affecting a vast majority of women in the world and having a negative impact on their quality of life and health ${ }^{9,42}$. Because the pathomechanism of VVC is still not fully understood, the achievement of therapeutic success is often difficult. Additionally, as the condition has a high tendency to relapse, it is often a challenge for both the patient and the clinician ${ }^{43}$. Previous studies on the development of vaginal mycosis indicate a multifactorial pathological mechanism, including the formation of biofilm by Candida strains and the growing resistance of yeastlike fungi to conventionally used antimycotics ${ }^{3,5,9,44}$. Among the etiological factors of VVC, C. albicans remains the most common, although other species are also increasingly often isolated, such as $C$. 
glabrata, C. Iusitaniae, C. parapsilosis, or C. kefyr ${ }^{3,5,9}$. Therefore, the search for new antimicrobial agents, including antifungal agents, also focuses on anti-biofilm activity.

AMPs (including lipopeptides) are among antimicrobial compounds that are of great interest for researchers, especially in recent years. These are compounds with a broad spectrum of activity and a different mechanism of action compared to traditional antibiotics, which makes it much more difficult for microorganisms to acquire resistance to them ${ }^{13-15,18}$. The compounds used in this study were ultrashort cationic lipopeptides (USCLs). In general, USCLs consist of at most 7 amino acid residues with a fatty acid attached. Usually, USCLs are rich in arginine or lysine, which makes them cationic (net positive charge). Owing to this structure, USCLs interact with the membrane bilayers of various microorganisms, permeabilize them and cause cell death ${ }^{13-15,18}$. Based on our previous study, compounds with the most potent antifungal and antibiofilm activities were selected. Two with linear structure, one modified by replacing one lysine residue $(\mathrm{K})$ with an arginine residue $(\mathrm{R})-\mathrm{C}_{16}-\mathrm{KKKK}^{-N \mathrm{NH}_{2}}(\mathrm{~L} 1)$ and $\mathrm{C}_{16}-\mathrm{KRKK}^{-\mathrm{NH}_{2}}$ (L2), as well as two cyclic analogs $-\mathrm{C}_{16}-{\mathrm{CKKKKC}-\mathrm{NH}_{2}}_{2}$ (C1) and $\mathrm{C}_{16}-{\mathrm{CKRKKC}-\mathrm{NH}_{2}}(\mathbf{C} 2)^{13}$. In the present study, antifungal activity of these lipopeptides was tested against 62 clinical strains of various Candida species isolated from VVC, both in planktonic and biofilm form. Reference strains of C. albicans ATCC 90028 and C. glabrata ATCC 15126 were also included. Moreover, combinations of the USCLs with fluconazole were tested for their potential synergistic or additive effect. The literature indicates the possibility of a beneficial effect of combinations of fluconazole with various AMPs against e.g. yeast-like fungi, most likely due to the different mechanisms of action of these two groups of compounds ${ }^{27,34-39}$. Meanwhile, to the best of our knowledge, no such experiments have been performed using ultrashort cationic lipopeptides against Candida isolated from VVC.

With one exception of a single $C$. Iusitaniae isolate (MIC $=64 \mu \mathrm{g} / \mathrm{mL})$, all tested strains were found to be susceptible to fluconazole-the most common MIC was $0.125 \mu \mathrm{g} / \mathrm{mL}$ or less (Fig. 1A). This is not an unusual situation; more surprising is the fact of so frequent clinical therapeutic failures with this mycostatic. Considering the multifactorial pathomechanism of vaginal invasion by yeast-like fungi, their ability to form highly resistant biofilm structure may be the major cause of the ineffectiveness of conventionally used azoles. Hence the focus of research on compounds with antibiofilm activity ${ }^{10,45-47}$. All four analyzed ultrashort lipopeptides showed activity against Candida strains. In the case of cyclic analogs, the achieved concentrations inhibiting the growth of planktonic cells are 2-3 times lower than those of their linear counterparts. The most common MIC value obtained for both cyclic lipopeptides was $4 \mu \mathrm{g} / \mathrm{mL} ; \approx 48 \%$ of cases for $\mathrm{C} 1$ and $\approx 52 \%$ for $\mathrm{C} 2$. Analogous concentrations for linear lipopeptides were $32 \mu \mathrm{g} / \mathrm{mL}(\approx 42 \%)$ and $16 \mu \mathrm{g} / \mathrm{mL}(\approx 47 \%)$, respectively. On the other hand, when comparing the activity of USCLs consisting of only lysine residues with lipopeptides with one arginine residue, the differences still seem to depend on the cyclic/linear structure of the compared compounds. In the case of cyclic analogs, the differences between MICs for $\mathbf{C} 1$ and $\mathbf{C} 2$ are virtually unnoticeable, which can be easily observed by comparing the histograms presented in Figs. 1B and 1C, which is consistent with previous studies on reference Candida strains ${ }^{13}$. Generally, the antimicrobial activity of linear L2 exceeds that of lipopeptide consisting exclusively of lysine. The most common MIC was $16 \mu \mathrm{g} / \mathrm{mL}$ and only $\approx 32 \%$ of the 
determined MICs exceeded this value, while in the case of L1, as much as $\approx 69 \%$ of MICs were higher than $16 \mu \mathrm{g} / \mathrm{mL}$. This finding is consistent with those of our earlier study in which activity against different Candida reference strains was analyzed ${ }^{13}$. Similarly to our previous reports, disulfide-cyclized lipopeptides were substantially more active against both biofilm and planktonic cultures than the corresponding parent molecules. It was mentioned by Neubauer et al. that cyclic lipopeptides seem to be much more active against various species of yeast-like fungi. There is an unconfirmed hypothesis that disulfide cyclized USCLs are transported inside the fungal cell, causing degradation of the cell membrane and its interior and leading to cell death ${ }^{48}$. Also, the potential advantage of linear analogs with the arginine residue, observed both by Neubauer and in this study, may support the first reports of the accumulation of protamine (salmon) rich in cationic arginine as necessary for anti-Candida activity 48 . The determined SIs (Table 1) of cyclic lipopeptides (5.50 and 8.83) are much higher than those of their linear counterparts $(0.28$ and 0.89$)$. Those results are in agreement with the literature. It has been shown that linear short cationic lipopeptides with hexadecanoic acid chain exhibited no selectivity between pathogens and normal human cells ${ }^{13,15,18,49}$. It is worth mentioning that for similar USCL, consisting of only two lysine residues $\left(\mathrm{C}_{16}-\mathrm{KK}-\mathrm{NH}_{2}\right)$, antifungal activity was already demonstrated, e.g. against Cryptococcus neoformans and dermatophytes 40,50 .

Similar conclusions are provided by the analysis of the obtained concentrations of biofilm eradication. While fluconazole failed to deal with Candida biofilm (Fig. 2A), all lipopeptides tested were capable of eradicating this structure (Figs. $2 \mathrm{~B}$ and $2 \mathrm{C}$ ). Again, cyclic analogs exhibited enhanced antibiofilm activity than linear parent molecules. While the most common MBEC value of both cyclic USCLs was $64 \mu \mathrm{g} / \mathrm{mL}$ (against $\approx 66 \%$ of strains for $\mathrm{C} 1$ and $\approx 76 \%$ for $\mathrm{C2}$ ), the MBEC distribution for both linear compounds was more variable, with a dominant value of $256 \mu \mathrm{g} / \mathrm{mL}$ (against $\approx 40 \%$ and $\approx 48 \%$ of strains, respectively). However, there are no substantial differences between the values of eradicating concentrations obtained for analogs composed only of lysine residues versus compounds enriched with an arginine residue; the histograms from the obtained distribution of values for both cyclic and linear lipopeptides are almost identical (Fig. 1B and 1C). The calculated GM_MBECs support this thesis. The results of research on biofilm are also consistent with our previous reports ${ }^{13}$. Higher minimum concentrations of compounds obtained for the biofilm structure compared to planktonic cells are not surprising. Biofilms, both bacterial and fungal, are characterized by a much higher resistance to antimicrobial agents than planktonic cells. Moreover, biofilm is associated with therapeutic failure. A single strain can be characterized as susceptible or resistant to fluconazole if examined against planktonic cells or biofilm, respectively 8,47 .

The present results showed that USCLs in combination with fluconazole can give various effects. The FIC indices obtained in the checkerboard method indicate that additive antifungal effect was obtained more frequently for a combination of fluconazole and linear lipopeptides than for cyclic ones. Preliminary experiments on 24 random Candida strains and combinations of all four USCLs with the tested azole showed that indifferent antifungal effect against vaginally isolated fungi was predominantly observed with cyclic USCLs ( $\approx 71 \%$ for $\mathbf{C} 1$ and $\approx 58 \%$ for $\mathbf{C}$ ). In the case of the L2 lipopeptide, the additive effect 
with fluconazole occurred more often than for its cyclic analog ( $\approx 46 \%$ vs $\approx 17 \%$ ). Moreover, additive effect was the most frequent with $\mathrm{L1}(\approx 63 \%)$. Analyzing the above data with regard to the Candida species ( 15 isolates of $C$. albicans vs 9 NCAC), the obtained results for cyclic lipopeptides are very similar - both $C$. albicans and other species represented an indifferent effect, while for strains from the NCAC group no additive effect was observed. A comparison of the effect of linear USCLs against $C$. albicans indicates the advantage of the analog consisting of four lysine residues, for which a vast majority has an additive effect (73\%). Studies on the linear compound enriched with arginine and combined with fluconazole revealed that it had an additive and indifferent effect on a similar percentage of strains (53\% and $47 \%$, respectively). Due to the small number of isolates from the NCAC group, a detailed analysis of the distribution of the obtained results seems unreliable.

Lipopeptide L1 was selected for further studies with fluconazole owing to promising results in the preliminary results discussed above. The cyclic analog was included in this study to learn how different structures of USCLs in combination with fluconazole can affect antifungal activity against strains derived from VVC. Although in the case of both tested cyclic compounds the indifference was definitely the dominant effect, in the case of $\mathbf{C 1}$, a negative (antagonistic) effect was observed less frequently than for C2 (8\% and $25 \%$, respectively). Hence, testing of the remaining pool of 40 strains was performed on a pair of USCLs composed only of lysine residues. The overall FIC index analysis for the entire pool of 62 isolates and 2 reference strains confirmed the predominant additive effect of the fluconazole-L1 combination: $84 \%$ in total, $91 \%$ including $C$. albicans strains and $55 \%$ of NCAC, although in this case, the relatively small number of isolates (11) should still be kept in mind. Interestingly, similar results were obtained for the cyclic lipopeptide, for which an additive effect was observed in $53 \%$ of cases, of which $60 \%$ against $C$. albicans. In the NCAC group, indifference remained the most frequent result (64\%). The literature has described the possibility of a favorable antifungal effect due to combinations of fluconazole with various AMPs ${ }^{34-39}$. The use of compounds with different mechanisms of action is generally recommended. Combined antifungal therapy has many potential benefits, such as enhancement of the fungicidal effect and broadening the spectrum of activity, which enable to fight polymicrobial infections, reduce the dose of the compounds, and thus also reduce dose-dependent toxicity as well as overcome the resistance of microorganisms ${ }^{51,52}$. It is noted that antimicrobial peptides interacting with the membrane bilayers could, in a way, sensitize Candida cells to fluconazole by increasing azole penetration into the cell, where its molecular target - 14a-lanosterol demethylase (Erg enzyme)-is located, involved in ergosterol synthesis. In effect, the composition of the cell membrane changes; it liquefies and increases the permeability for $\mathrm{K}^{+}$and ATP causing a fungistatic effect ${ }^{53}$. On the other hand, the interaction of fluconazole with the cell membrane may enhance its permeabilization by various AMPs, including lipopeptides, and enhance their fungicidal activity $51,54,55$. Other mechanisms that may be responsible for the synergistic effect of combining triazoles with compounds with a different mechanism of action include sequential inhibition of different stages in the mutual biochemical pathway or simultaneous interaction with the Candida cell wall and/or membrane ${ }^{51}$. However, this hypothesis remains unconfirmed as of today. 
Last but not least, there is one more interesting aspect of research using the checkerboard method. Knowing the general nature of the interaction of the combination of fluconazole with the lipopeptide against Candida, the next step is to select the most favorable and effective concentrations of both compounds to combat fungi. For this purpose, the individual FIC (as the FIC index is the arithmetic mean of 8 different FIC values) obtained for a given pair of compounds should be interpreted and the corresponding concentrations selected. In this way, the most favorable (the lowest) FIC for each of the isolates was analyzed in both fluconazole-L1 and fluconazole-C1 combinations. In $72 \%$ of strains (75\% of C. albicans, and $55 \%$ of NCAC) there was such a combination of the concentrations of linear lipopeptide and FLC for which FIC indicated a synergistic effect (FIC $\leq 0.5)$. The most beneficial FICs for the cyclic lipopeptide still showed a predominant additive effect (61\%), although a synergistic effect was also observed (23\%). A detailed analysis revealed that the concentration of $L 1$ in combination with fluconazole that result in synergy is up to four-fold lower ( $2 \mathrm{vs.} 16 \mu \mathrm{g} / \mathrm{mL})$ than when lipopeptide is used separately (MIC value, Table 2). The literature contains an increasing body of reports about the results of similar studies of interactions of different compounds, not always having any activity against Candida alone, indicating a synergistic effect of their combinations with a number of antimycotics, including triazoles. There is a great interest in research on amphiphilic Lactoferrin (LF and its derivatives - cationic peptides), the use of which together with fluconazole (and not only) results in a significant increase in fungistatic activity and a decrease in MIC values ${ }^{56-59}$. Although the mechanisms responsible for this phenomenon remain unexplained, attention is drawn to the beneficial effects of cationic compounds, such as LF, which may enhance the hydrophobicity of the surface of microbial cells and potentiate the antifungal activity of other compounds ${ }^{57}$. Another example is the advantageous synergistic effect of combinations with fluconazole of such positively charged compounds as microbicidal cationic oligomers, styrylpyridinium compounds, novel antimicrobial peptides such as KABT-AMP derivatives or ToAP2 $51,55,60,61$. Recently, the synergism of fluconazole with surfactin (SU) against $C$. albicans has been described in more detail. Suchodolski et al. showed that SU binds to chitin and $\beta$-glucan on the surface of fungal cells, exposing it to the components of the host's immune system. However, to achieve the necessary effect, there seems to be required a reduction or complete lack of ergosterol, resulting in the corresponding changes in cell membrane and this is ensured by the presence of fluconazole 27 . Derivatives of quaternary ammonium compounds (QAC) are other compounds whose activity is similar to that of cationic surfactants and which at the same time have a structure similar to lipopeptides (positive charge, presence of a lipid chain). One representative of this group, compound $K 21$, has recently been tested for antifungal activity for the first time. It seems to be an effective alternative to fluconazole against Candida strains resistant to this mycostatic. K21 also shows synergism with triazoles towards NCAC, including $C$. dubliniensis and $C$. tropicalis, but no such effect was observed for $C$. albicans ${ }^{62}$. Meanwhile, a combination of another quaternary ammonium compound, domiphen bromide, with miconazole (imidazole) showed a synergistic effect against not only Candida planktonic cells, but also a biofilm - although this effect did not occur in the case of triazoles, including fluconazole ${ }^{63}$. On the other hand, the mechanism of action of benzimidazolium-based QAC gemini surfactants was identified as influence on ergosterol synthesis in a manner similar to that of triazoles. Nevertheless, benzimidazolium- 
based QACs were more effective and their combination with fluconazole results in synergistic effect against various Candida species ${ }^{64}$. There are also reports in the literature about the synergistic effect of USCL with a structure similar to L1 and L2 with fluconazole and other triazoles, as well as with amphotericin B or terbinafine against Cryptococcus neoformans fungi and various representatives of dermatophytes 40,50 . However, the mechanism of interaction of the above-mentioned compounds alone and in combination against fungi remains unclear. The literature and our results together clearly demonstrate the enormous potential of ultrashort cationic lipopeptides as compounds enhancing the activity of the existing antimycotics.

Therefore, the results achieved in this work constitute another important premise in the search for antifungal compounds and their combinations with conventional mycobiotics. Moreover, our findings can contribute to the broadening of knowledge in the search for mechanisms involved in the interactions of various cationic compounds with target cells and other antimicrobial compounds. Importantly, the most serious problems to be solved before the actual use of USCLs in the treatment of fungal infections are their relatively high toxicity and unsatisfactory selectivity between microorganisms and human cells ${ }^{15,18}$. The use of combination therapy has a potential to significantly reduce the concentration of lipopeptides effective against Candida and to reduce toxicity towards human cells.

\section{Conclusions}

The results of this study performed with clinical isolates of Candida confirmed high antifungal potency of USCLs which have previously been studied only with reference yeast strains. Among the four tested lipopeptides, the cyclic compounds $\mathrm{C} 1$ and $\mathrm{C} 2\left(\mathrm{C}_{16}-\mathrm{CKKKKC}-\mathrm{NH}_{2}\right.$ and $\mathrm{C}_{16}$ - $\left.\mathrm{CKRKKC}-\mathrm{NH}_{2}\right)$ showed higher activity against planktonic cells and biofilm of Candida isolated from VVC than their linear analogs, L1 and $\mathbf{L} 2\left(\mathrm{C}_{16}-\mathrm{KKKK}^{-\mathrm{NH}_{2}}\right.$ and $\left.\mathrm{C}_{16}-\mathrm{KRKK}^{-\mathrm{NH}_{2}}\right)$. Both cyclic counterparts were also more selective to pathogens over human cells, as demonstrated by SIs. Although the linear lipopeptide with a single arginine residue appeared to be more active against planktonic cells than the USCL consisting of only four lysine residues, no similar relationship was observed for biofilm eradicating concentrations. With regard to VVC, it would be undoubtedly worthwhile to conduct studies on the toxicity of these compounds towards vaginal epithelium cell lines and to take into account a larger number of strains from the NCAC group. The study on the interactions of fluconazole combined with lipopeptides showed the advantage of linear USCLs over cyclic ones, especially $\mathrm{C}_{16}-\mathrm{KKKK}^{-} \mathrm{NH}_{2}$. The concentrations of the linear lipopeptides causing a synergistic effect against Candida turned out to be at least four-fold lower than when lipopeptides were used separately. Presumably, it would be possible to use a combination therapy, achieving beneficial fungicidal effects owing to the use of compounds with different mechanisms of action, against which the development of resistance would be significantly impeded, at low non-toxic and therefore safer concentrations.

\section{Materials And Methods}




\section{Lipopeptides Synthesis}

The compounds were obtained by using the method reported previously ${ }^{13}$. Lipopeptides were synthesized manually by solid-phase Fmoc/tBu methodology. Polystyrene resin modified by Rink Amide linker was used as the solid support (loading ca. $1.0 \mathrm{mmol} / \mathrm{g}$; Orpegen Peptide Chemicals $\mathrm{GmbH}$, Heidelberg, Germany). Deprotection of the Fmoc group was performed with a 20\% (v/v) piperidine (Iris Biotech $\mathrm{GmbH}$, Marktredwitz, Germany) solution in DMF ( $\mathrm{N}, \mathrm{N}$-dimethylformamide; $\mathrm{POCH}$, Avantor, Gliwice, Poland) for $15 \mathrm{~min}$. Acylation was conducted with a mixture of DIC:OxymaPure:Fmoc-AA-OH (mole ratio 1:1:1; DIC - N,N'-diisopropylcarbodiimide) dissolved in DMF:DCM (1:1, v/v; DCM - dichloromethane, Chempur, Piekary Slaskie, Poland) in fourfold excess based on the resin for $1.5 \mathrm{~h}$ (DIC and OxymaPure; Iris Biotech GmbH, Marktredwitz, Germany). Fmoc-L-Arg(Pbf)-OH, Fmoc-L-Lys(Boc)-OH, Fmoc-L-Cys(Trt)$\mathrm{OH}$ (amino acids were purchased from Orpegen Peptide Chemicals GmbH Heidelberg, Germany), and hexadecanoic acid (C16, palmitic acid; Merck, Darmstadt, Germany) were used in coupling reactions. After deprotection and coupling reactions, the resin was rinsed with DMF and DCM and subsequently the chloranil test was carried out. The peptides were cleaved from the resin using one of the mixtures; (A) TFA (trifluoroacetic acid; Apollo Scientific, Denton, UK), EDT (1,2-ethanedithiol; Merck, Darmstadt, Germany), TIS (triisopropylsilane; Iris Biotech GmbH, Marktredwitz, Germany), and deionized water (92.5:2.5:2.5:2.5, $\mathrm{v} / \mathrm{v} / \mathrm{v} / \mathrm{v}) ;(\mathrm{B}) \mathrm{TFA}, \mathrm{TIS}$, and deionized water (95:2.5:2.5, v/v/v). Mixture A was used with peptides containing a cysteine residue, whereas mixture $B$ was used for the remaining peptides. Cleavage was accomplished within $1.5 \mathrm{~h}$ under stirring. Then the peptides were precipitated with cooled diethyl ether ( $\mathrm{POCH}$, Avantor, Gliwice, Poland) and lyophilized. The crude peptide with cysteine was dissolved in $20 \%$ ( $\mathrm{v} / \mathrm{v})$ acetic acid (Chempur, Piekary Slaskie, Poland) solution $(0.5 \mathrm{~g} / \mathrm{L})$ and oxidized with iodine to obtain the peptide with intramolecular disulfide bridge. The peptides were purified by RP-HPLC. Pure fractions $(>95 \%$, HPLC) were collected and lyophilized. The identity of all compounds was confirmed by mass spectrometry (ESI-MS). The sequences of the synthesized lipopeptides were as follows: linear $\mathrm{C}_{16}-\mathrm{KKKK}$ $\mathrm{NH}_{2}$ (L1) and $\mathrm{C}_{16}-\mathrm{KRKK}^{-\mathrm{NH}_{2}}$ (L2), cyclic: $\mathrm{C}_{16}-\mathrm{CKKKKC}^{-\mathrm{NH}_{2}}$ (C1) and $\mathrm{C}_{16}-{\mathrm{CKRKKC}-\mathrm{NH}_{2}}_{2}$ (C2).

\section{Candida Strains}

Microbiological assays were performed on 62 clinical isolates of various Candida species. The vast majority of strains were identified as $C$. albicans (52), while the remaining strains belonged to the NCAC group: i.e. C. glabrata (5), C. Iusitaniae (2), C. kefyr (2), and C. parapsilosis (1). All strains were originally isolated from the vaginas of women with vulvovaginal candidiasis and were deposited in the Internal Collection of the Department of Microbiology, Wroclaw Medical University. Two reference strains of $C$. albicans ATCC 90028 and C. glabrata ATCC 15126 (PCM, Polish Academy of Sciences, Wroclaw) were included in all experiments.

The study protocol was approved by the local Bioethics Committee of Wrocław Medical University (No. $774 / 2018$, approval date: December 27, 2018). All experiments were performed in accordance with relevant guidelines and regulations. 
The first part of the study aimed to determine minimum inhibitory concentrations (MICs) of fluconazole and four lipopeptides against Candida strains. The research was carried out in accordance with Clinical and Laboratory Standards Institute guidelines ${ }^{65}$. Suspensions of Candida strains (subcultured for 24 hours on Sabouraud Dextrose Agar with chloramphenicol at a concentration of $100 \mathrm{mg} / \mathrm{L}$ ) in sterile $0.9 \%$ $\mathrm{NaCl}$ were diluted in RPMI 1640 (Merck, KGaA, Darmstadt, Germany) to a final concentration of $1-5 \times 10^{3}$ CFU per $\mathrm{mL}$. The test compounds dissolved in DMSO (Merck, KGaA, Darmstadt, Germany) for fluconazole and in sterile distilled water for lipopeptides were diluted in RPMI 1640 on 96-well polystyrene plates to a final range of concentrations $0.125-128 \mu \mathrm{g} / \mathrm{mL}$ (fluconazole) and $0.5-256 \mu \mathrm{g} / \mathrm{mL}$ (USCLs). After the addition of inoculums, all plates were incubated for 24 hours at $37^{\circ} \mathrm{C}$. In the case of fungistatic fluconazole the MIC value is defined as the concentration which inhibits at least $50 \%$ of fungal growth. In order to determine the most accurate MIC end-point value, cell densities were determined spectrophotometrically at $530 \mathrm{~nm}$ (BiochromAsys UVM 340 Microplate Spectrophotometer, Biochrom Ltd, USA). To calculate the MIC value, the following equation was used: (OD well - OD background)/(OD growth_control - OD background) $\times 100 \%$. Minimum inhibitory concentrations of lipopeptides were the lowest concentrations at which inhibition of fungal growth was noticeable. All experiments were conducted in triplicate and included growth and a sterility control.

\section{Minimum biofilm eradication concentration}

The determination of minimum biofilm eradication concentrations (MBECs) of all five compounds was performed on 96-well polystyrene flat-bottom plates. 24-hour cultures of Candida were diluted with RPMI 1640 to obtain a final concentration of $1-5 \times 10^{6}$ cells per $\mathrm{mL}$ and $100 \mu \mathrm{L}$ of cell suspension was added into each well of the test plate. The plates were incubated for $24 \mathrm{~h}$ at $37^{\circ} \mathrm{C}$ in order to produce a mature biofilm. After incubation the biofilms were rinsed three times with sterile $0.9 \% \mathrm{NaCl}$. Subsequently, fluconazole was added with a final range of concentrations of $1-512 \mu \mathrm{g} / \mathrm{mL}$, while the lipopeptides concentration ranged between 0.5 and $256 \mu \mathrm{g} / \mathrm{mL}$. The plates were again incubated overnight at $37^{\circ} \mathrm{C}$. Visualization of results was carried out with a MTT solution (3-(4,5-dimethyl-2-thiazolyl)-2,5-diphenyl- $2 \mathrm{H}$ tetrazolium bromide), Merck, KGaA, Darmstadt, Germany) which is reduced by metabolically active sessile cells of biofilm to purple/navy blue formazan compounds ${ }^{66}$. Yellow MTT solution was added to each well of the plates and incubated for 3 hours in the dark at $37^{\circ} \mathrm{C}$. MBECs were the lowest concentrations of the compounds at which no color change was observed (no metabolically active yeast cells were present) as compared to the positive and negative controls. All experiments were conducted in triplicate.

\section{Fractional inhibitory concentration index}

The checkerboard method was used to determine fractional inhibitory concentration index (FICi) ${ }^{67}$. Each lipopeptide was prepared on a 96-well polystyrene plate with concentrations decreasing horizontally ( 1 to 8) while the concentrations of fluconazole were decreasing vertically ( $\mathrm{A}$ to $\mathrm{H})$. The highest lipopeptide 
and fluconazole concentrations were set at $2 \times \mathrm{MIC}$ individually for each strain. Then the lipopeptides and fluconazole were serially diluted. In each well of the plates prepared as above, different lipopeptidefluconazole concentrations were obtained. Inoculums of Candida strains were prepared as described for the determination of MIC (final concentration of $1-5 \times 10^{3} \mathrm{CFU}$ per $\mathrm{mL}$ in RPMI 1640). After the yeast suspension was added, the plates were incubated for 24 hours at $37^{\circ} \mathrm{C}$. Inhibition of Candida growth was assessed visually. To calculate the FIC index, the following formula was used:

\section{See formula in the supplementary files.}

MIC values of compound A (lipopeptide) and B (fluconazole) were obtained in the first part of the research. $A$ and $B$ values were concentrations of the compounds determined using the checkerboard method. The sum of the ratios of these values $\left(\mathrm{FIC}_{A}, \mathrm{FIC}_{\mathrm{B}}\right.$ ) was $\mathrm{FIC}$ and after it was divided by $\mathrm{n}$ (number of FICs), the FIC index was obtained. Interpretation of the results was consistent with EUCAST guidelines 41 as follows: FICi $\leq 0.5$ indicates synergy (SYN), $>0.5$ to $\leq 1.0$ - addition (ADD), >1.0 to $\leq 2.0$ indifference (IND) and $\mathrm{FICi}>2.0$ means antagonism (ANT).

\section{Declarations}

\section{Acknowledgements}

This research was financially supported by the Ministry of Health subvention according to number of STM.A130.20.102 from the IT Simple system of Wroclaw Medical University.

\section{Author contributions}

P.C, J.N. and G.G. designed this study. P.C. performed the experiments. P.C. and J.N. analyzed the results. P.C. and D.N. wrote the manuscript and prepared the figures. W.K. and G.G. revised the manuscript. All authors read and approved the final version of this manuscript.

\section{Additional information}

\section{Competing Interests Statement}

The authors declare that they have no competing interests.

\section{Data Availability Statement}

The datasets generated during and/or analyzed during the current study are available from the corresponding author on reasonable request.

\section{References}

1. Sobel, J. D. Vulvovaginal candidosis. Lancet369, 1961-1971 (2007). 
2. Gonçalves, B. et al. Vulvovaginal candidiasis: epidemiology, microbiology and risk factors. Crit. Rev. Microbiol.42, 905-927 (2016).

3. Muzny, C. A. \& Schwebke, J. R. Biofilms: an underappreciated mechanism of treatment failure and recurrence in vaginal infections. Clin. Infect. Dis.61, 601-606 (2015).

4. Brandolt, T. M. et al. Prevalence of Candida spp. in cervical-vaginal samples and the in vitro susceptibility of isolates. Brazilian J. Microbiol.48, 145-150 (2017).

5. Hacioglu, M., Guzel, C. B., Savage, P. B. \& Seher Birteksoz Tan, A. Antifungal susceptibilities, in vitro production of virulence factors and activities of ceragenins against Candida spp. Isolated from vulvovaginal candidiasis. Med. Mycol.57, 291-299 (2019).

6. Sherry, L. et al. Biofilms formed by isolates from recurrent vulvovaginal candidiasis patients are heterogeneous and insensitive to fluconazole. Antimicrob. Agents Chemother.61, 1-4 (2017).

7. Swidsinski, A. et al. Vulvovaginal candidiasis: histologic lesions are primarily polymicrobial and invasive and do not contain biofilms. Am. J. Obstet. Gynecol.220, 91.e1-91.e8 (2019).

8. Harriott, M. M., Lilly, E. A., Rodriguez, T. E., Fidel, P. L. \& Noverr, M. C. Candida albicans forms biofilms on the vaginal mucosa. Microbiology156, 3635-3644 (2010).

9. Paiva, L. C. F., Vidigal, P. G., Donatti, L., Svidzinski, T. I. E. \& Consolaro, M. E. L. Assessment of in vitro biofilm formation by Candida species isolates from vulvovaginal candidiasis and ultrastructural characteristics. Micron43, 497-502 (2012).

10. Rodríguez-Cerdeira, C. et al. Biofilms and vulvovaginal candidiasis. Colloids Surfaces $B$ Biointerfaces174, 110-125 (2019).

11. Harriott, M. M. \& Noverr, M. C. Importance of Candida-bacterial polymicrobial biofilms in disease. Trends Microbiol.19, 557-563 (2011).

12. Dawgul, M., Barańska-Rybak, W., Bielińska, S., Nowicki, R. \& Kamysz, W. Wpływ peptydów przeciwdrobnoustrojowych na biofilm Candida. Alerg. Astma Immunol.15, 220-225 (2010).

13. Neubauer, D. et al. Effect of disulfide cyclization of ultrashort cationic lipopeptides on antimicrobial activity and cytotoxicity. Int. J. Mol. Sci.21, 1-30 (2020).

14. Czechowicz, P. \& Nowicka, J. Antimicrobial activity of lipopeptides. Postep. Mikrobiol.57, 213-227 (2018).

15. Mangoni, M. L. \& Shai, Y. Short native antimicrobial peptides and engineered ultrashort lipopeptides: Similarities and differences in cell specificities and modes of action. Cell. Mol. Life Sci.68, 22672280 (2011).

16. Jones, L., Hobden, C. \& O'Shea, P. Use of a real-time fluorescent probe to study the electrostatic properties of the cell surface of Candida albicans. Mycol. Res.99, 969-976 (1995).

17. Lohan, S., Cameotra, S. S. \& Bisht, G. S. Systematic study of non-natural short cationic lipopeptides as novel broad-spectrum antimicrobial agents. Chemical Biology and Drug Design vol. 82 (2013).

18. Makovitzki, A., Avrahami, D. \& Shai, Y. Ultrashort antibacterial and antifungal lipopeptides. Proc. Natl. Acad. Sci. U. S. A.103, 15997-16002 (2006). 
19. Greber, K. E. Synthesis and Surface Activity of Cationic Amino Acid-Based Surfactants in Aqueous Solution. J. Surfactants Deterg.20, 1189-1196 (2017).

20. Serrano, G. N., Zhanel, G. G. \& Schweizer, F. Antibacterial activity of ultrashort cationic lipo-ß-peptides. Antimicrob. Agents Chemother.53, 2215-2217 (2009).

21. Hensel, B. et al. Low temperature preservation of porcine semen: influence of short antimicrobial lipopeptides on sperm quality and bacterial load. Sci. Rep.10, 1-12 (2020).

22. Ciandrini, E. et al. Antimicrobial Activity of Different Antimicrobial Peptides (AMPs) Against Clinical Methicillin-resistant Staphylococcus aureus (MRSA). Curr. Top. Med. Chem.18, 2116-2126 (2018).

23. Greber, K. E., Dawgul, M., Kamysz, W. \& Sawicki, W. Cationic net charge and counter ion type as antimicrobial activity determinant factors of short lipopeptides. Front. Microbiol.8, 1-10 (2017).

24. Sikorska, E. et al. Self-assembly and interactions of short antimicrobial cationic lipopeptides with membrane lipids: ITC, FTIR and molecular dynamics studies. Biochim. Biophys. Acta Biomembr.1838, 2625-2634 (2014).

25. Desmyttere, H. et al. Antifungal activities of bacillus subtilis lipopeptides to two venturia inaequalis strains possessing different tebuconazole sensitivity. Front. Microbiol.10, 1-10 (2019).

26. Ceresa, C., Rinaldi, M. \& Fracchia, L. Synergistic activity of antifungal drugs and lipopeptide AC7 against <em>Candida albicans</em> biofilm on silicone. AIMS Bioeng.4, 318-334 (2017).

27. Suchodolski, J. et al. Fluconazole and lipopeptide surfactin interplay during Candida albicans plasma membrane and cell wall remodeling increases fungal immune system exposure. Pharmaceutics12, (2020).

28. Liu, X. et al. Optimization for the production of surfactin with a new synergistic antifungal activity. PLoS One7, 1-9 (2012).

29. Maget-Dana, R., Thimon, L., Peypoux, F. \& Ptak, M. Surfactin/iturin A interactions may explain the synergistic effect of surfactin on the biological properties of iturin A. Biochimie74, 1047-1051 (1992).

30. Tabbene, O. et al. Synergistic fungicidal activity of the lipopeptide bacillomycin D with amphotericin B against pathogenic Candida species. FEMS Yeast Res.15, fov022 (2015).

31. Ramachandran, R. et al. Evaluation of antifungal efficacy of three new cyclic lipopeptides of the class bacillomycin from Bacillus subtilis RLID 12.1. Antimicrob. Agents Chemother.62, 1-11 (2018).

32. Kai, H. et al. Synergistic antifungal activity of KB425796-C in combination with micafungin against Aspergillus fumigatus and its efficacy in murine infection models. J. Antibiot. (Tokyo).66, 479-484 (2013).

33. Dimkić, l. et al. Additive and synergistic effects of Bacillus spp. isolates and essential oils on the control of phytopathogenic and saprophytic fungi from medicinal plants and marigold seeds. Biol. Contro/87, 6-13 (2015).

34. Sun, W., Zhang, L., Lu, X., Feng, L. \& Sun, S. The synergistic antifungal effects of sodium phenylbutyrate combined with azoles against Candida albicans via the regulation of the Ras-cAMP- 
PKA signalling pathway and virulence. Can. J. Microbiol. Can.65, 105-115 (2019).

35. Taveira, G. B. et al. Thionin-like peptide from Capsicum annuum fruits: Mechanism of action and synergism with fluconazole against Candida species. BMC Microbiol.16, 1-13 (2016).

36. de Aguiar, F. L. L. et al. The antiproliferative peptide Ctn[15-34] is active against multidrug-resistant yeasts Candida albicans and Cryptococcus neoformans. Journal of Applied Microbiology vol. 128 (2020).

37. Maurya, I. K. et al. Mechanism of action of novel synthetic dodecapeptides against Candida albicans. Biochim. Biophys. Acta - Gen. Subj.1830, 5193-5203 (2013).

38. Mora-Navarro, C., Caraballo-Leõn, J., Torres-Lugo, M. \& Ortiz-Bermúdez, P. Synthetic antimicrobial $\beta$ peptide in dual-treatment with fluconazole or ketoconazole enhances the in vitro inhibition of planktonic and biofilm Candida albicans. J. Pept. Sci.21, 853-861 (2015).

39. Maurya, I. K. et al. Antifungal activity of novel synthetic peptides by accumulation of reactive oxygen species (ROS) and disruption of cell wall against Candida albicans. Peptides32, 1732-1740 (2011).

40. Simonetti, O. et al. In vitro activity of the lipopeptide derivative (Pal-lys-lys-NH 2), alone and in combination with antifungal agents, against clinical isolates of dermatophytes. Br. J. Dermatol.161, 249-252 (2009).

41. Diseases, I. Terminology relating to methods for the determination of susceptibility of bacteria to antimicrobial agents. Clin. Microbiol. Infect.6, 503-508 (2000).

42. Sherry, L. et al. Biofilms formed by isolates from patients are heterogeneous and insensitive to fluconazole. Antimicrob Agents Chemother61, 1-4 (2017).

43. Swidsinski, A. et al. Vulvovaginal candidiasis: histologic lesions are primarily polymicrobial and invasive and do not contain biofilms. Am. J. Obstet. Gynecol.220, 91.e1-91.e8 (2019).

44. Tulasidas, S., Rao, P., Bhat, S. \& Manipura, R. A study on biofilm production and antifungal drug resistance among Candida species from vulvovaginal and bloodstream infections. Infect. Drug Resist.11, 2443-2448 (2018).

45. Capoci, I. R. G. et al. Propolis is an efficient fungicide and inhibitor of biofilm production by vaginal Candida albicans. Evidence-based Complement. Altern. Med.2015, (2015).

46. Consolaro, M. E. L., Albertoni, T. A., Svidzinski, A. E., Peralta, R. M. \& Svidzinski, T. I. E. Vulvovaginal candidiasis is associated with the production of germ tubes by Candida albicans. Mycopathologia159, 501-507 (2005).

47. Scarsini, M. et al. Antifungal activity of cathelicidin peptides against planktonic and biofilm cultures of Candida species isolated from vaginal infections. Peptides71, 211-221 (2015).

48. Nagao, J. et al. Antifungal activity in vitro and in vivo of a salmon protamine peptide and its derived cyclic peptide against Candida albicans. FEMS Yeast Res.17, fow099 (2016).

49. Dawgul, M. A. et al. In vitro evaluation of cytotoxicity and permeation study on lysine- and argininebased lipopeptides with proven antimicrobial activity. Molecules22, 3-9 (2017). 
50. Barchiesi, F. et al. In vitro activity of the synthetic lipopeptide PAL-Lys-Lys-NH2 alone and in combination with antifungal agents against clinical isolates of Cryptococcus neoformans. Peptides28, 1509-1513 (2007).

51. Yuan, Y., Zhou, F., Su, H. \& Zhang, Y. Structural design of microbicidal cationic oligomers and their synergistic interaction with azoles against Candida albicans. Sci. Rep.9, 1-11 (2019).

52. Bozkurt-Guzel, C., Hacioglu, M. \& Savage, P. B. Investigation of the in vitro antifungal and antibiofilm activities of ceragenins CSA-8, CSA-13, CSA-44, CSA-131, and CSA-138 against Candida species. Diagn. Microbiol. Infect. Dis.91, 324-330 (2018).

53. Venisse, N., Grégoire, N., Marliat, M. \& Couet, W. Mechanism-based pharmacokineticpharmacodynamic models of in vitro fungistatic and fungicidal effects against Candida albicans. Antimicrob. Agents Chemother.52, 937-943 (2008).

54. Czechowicz, P., Jaśkiewicz, M., Neubauer, D., Gościniak, G. \& Kamysz, W. Anticandidal Activity of Omiganan and Its Retro Analog Alone and in Combination with Fluconazole. Probiotics Antimicrob. Proteins (2021) doi:10.1007/s12602-021-09757-9.

55. do Nascimento Dias, J. et al. Mechanisms of action of antimicrobial peptides ToAP2 and NDBP-5.7 against Candida albicans planktonic and biofilm cells. Sci. Rep.10, 1-14 (2020).

56. Fernandes, K. E. \& Carter, D. A. The antifungal activity of lactoferrin and its derived peptides: Mechanisms of action and synergy with drugs against fungal pathogens. Front. Microbiol.8, 1-10 (2017).

57. Kobayashi, T. et al. Synergistic antifungal effect of lactoferrin with azole antifungals against candida albicans and a proposal for a new treatment method for invasive candidiasis. Jpn. J. Infect. Dis.64, 292-296 (2011).

58. Lupetti, A. et al. Synergistic activity of the N-terminal peptide of human lactoferrin and fluconazole against Candida species. Antimicrob. Agents Chemother.47, 262-267 (2003).

59. Bondaryk, M., Staniszewska, M., Zielińska, P. \& Urbańczyk-Lipkowska, Z. Natural antimicrobial peptides as inspiration for design of a new generation antifungal compounds. Journal of Fungi vol. 3 (2017).

60. Vaitkienè, S. et al. Antifungal activity of styrylpyridinium compounds against Candida albicans. Chem. Biol. Drug Des.97, 253-265 (2021).

61. Lum, K. Y. et al. Activity of novel synthetic peptides against Candida albicans. Sci. Rep.5, (2015).

62. John, C. N., Abrantes, P. M. D. S., Prusty, B. K., Ablashi, D. V. \& Africa, C. W. J. K21 compound, a potent antifungal agent: Implications for the treatment of fluconazole-resistant HIV-associated Candida species. Front. Microbiol.10, (2019).

63. Tits, J. et al. Combination of miconazole and domiphen bromide is fungicidal against biofilms of resistant candida spp. Antimicrob. Agents Chemother.64, (2020).

64. Wani, F. A. et al. Synthesis of Novel Benzimidazolium Gemini Surfactants and Evaluation of Their Anti-Candida Activity. ACS Omega4, 11871-11879 (2019). 
65. Pfaller, M. A. et al.Reference method for broth dilution antifungal susceptibility testing of yeasts; approved standard - second edition serving the world's medical science community through voluntary consensus. vol. 22 (2002).

66. Krom, B. P. et al.Conditions for Optimal Candida Biofilm Development in Microtiter Plates [in:] Candida albicans methods and protocols. (Humana Press, a part of Springer SciencepBusiness Media, LLC, 2009).

67. Nilius, A. M. Antimicrobial pharmacodynamics in theory and clinical practice. Shock vol. 17 (2002).

\section{Figures}




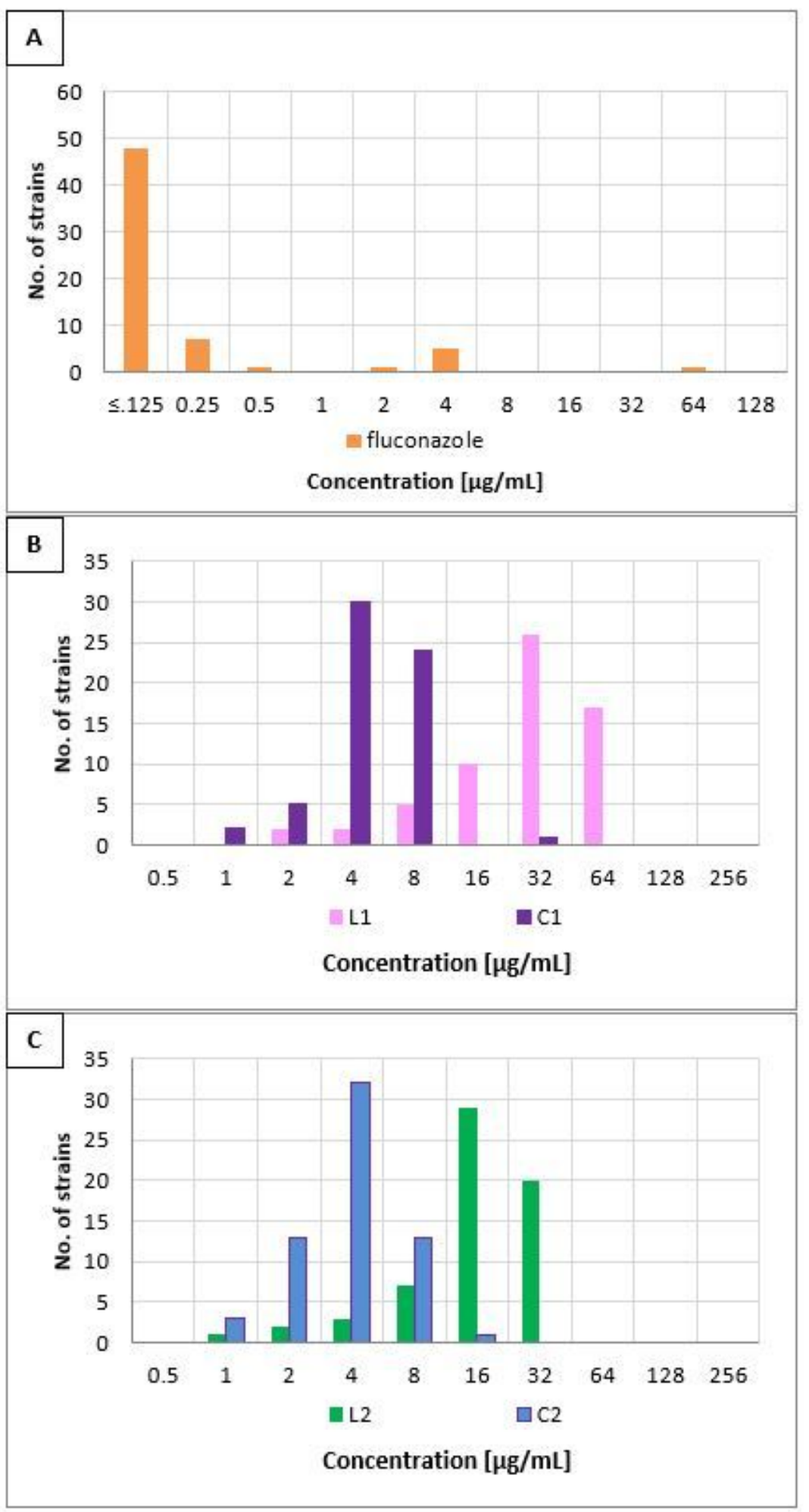

Figure 1

MIC value distribution of the tested compounds: (A) - fluconazole, (B) - lipopeptides L1 and C1, (C) lipopeptides L2 and C2. 


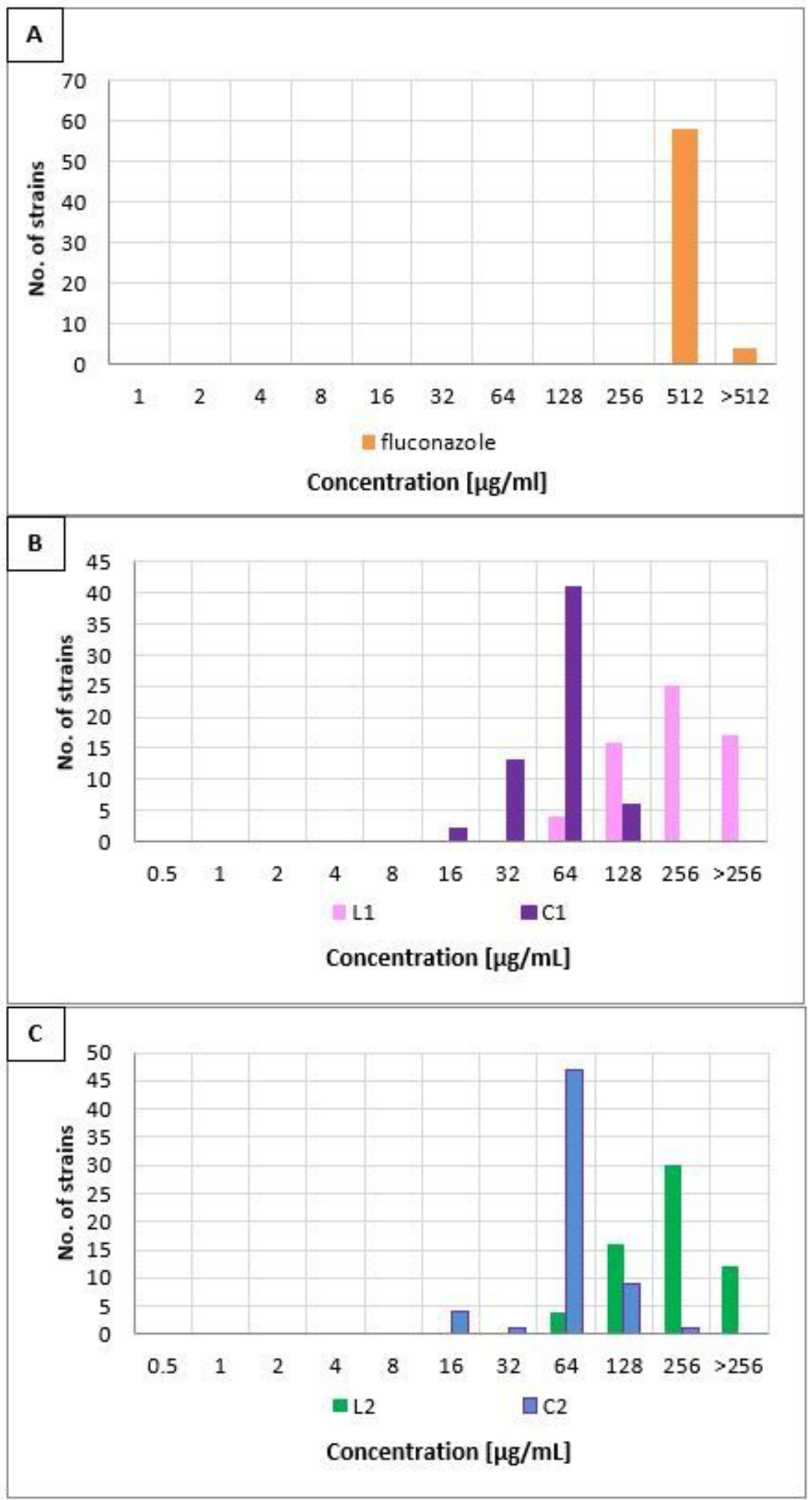

Figure 2

MBEC value distribution of the tested compounds: (A) - fluconazole, (B) - lipopeptides L1 and C1, (C) lipopeptides L2 and C2. 

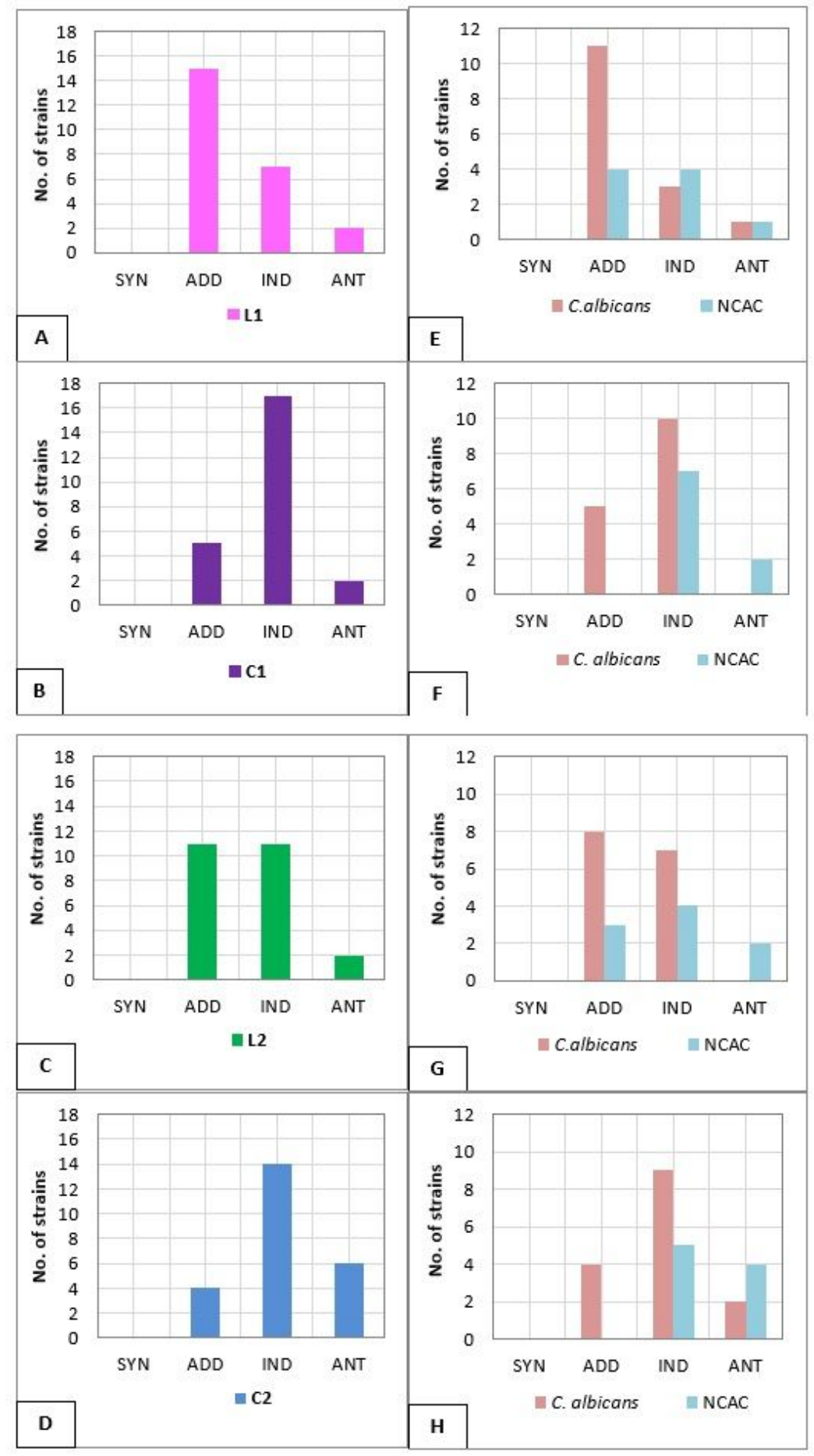

\section{Figure 3}

Interpretation of the determined FIC indices (SYN - synergy, ADD - addition, IND - indifference, ANT antagonism) : (A) L1; (B) C1; (C) L2; (D) C2; and with differentiation between C. albicans and NCAC isolates: $(\mathrm{E}) \mathrm{L} 1 ;(\mathrm{F}) \mathrm{C} 1 ;(\mathrm{G}) \mathrm{L} 2 ;(\mathrm{H}) \mathrm{C} 2$. 

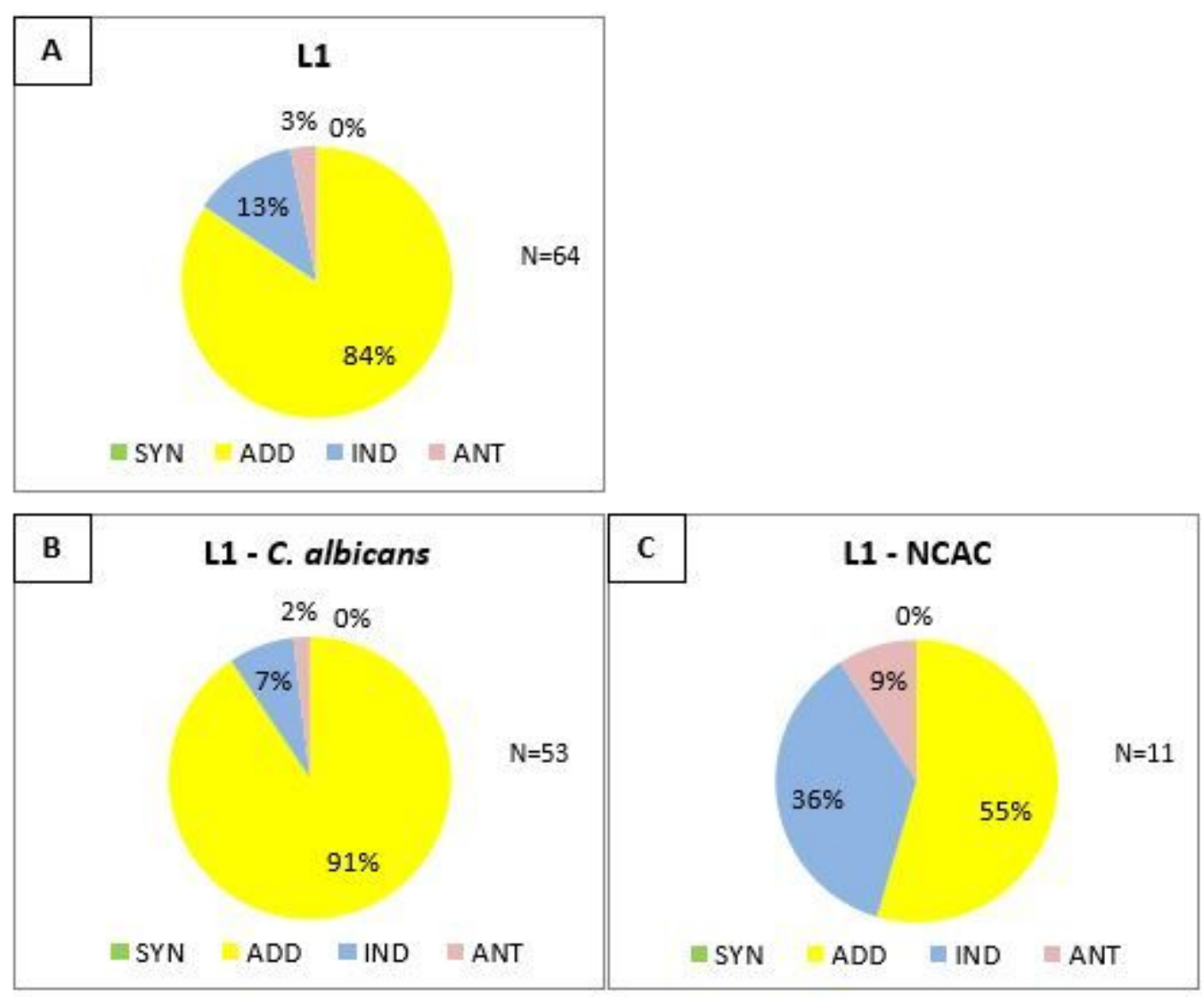

Figure 4

Distribution of FIC indices for combination fluconazole-L1; (A) total - 64 strains; (B) C. albicans - 53 strains; (C) NCAC - 11 strains. 

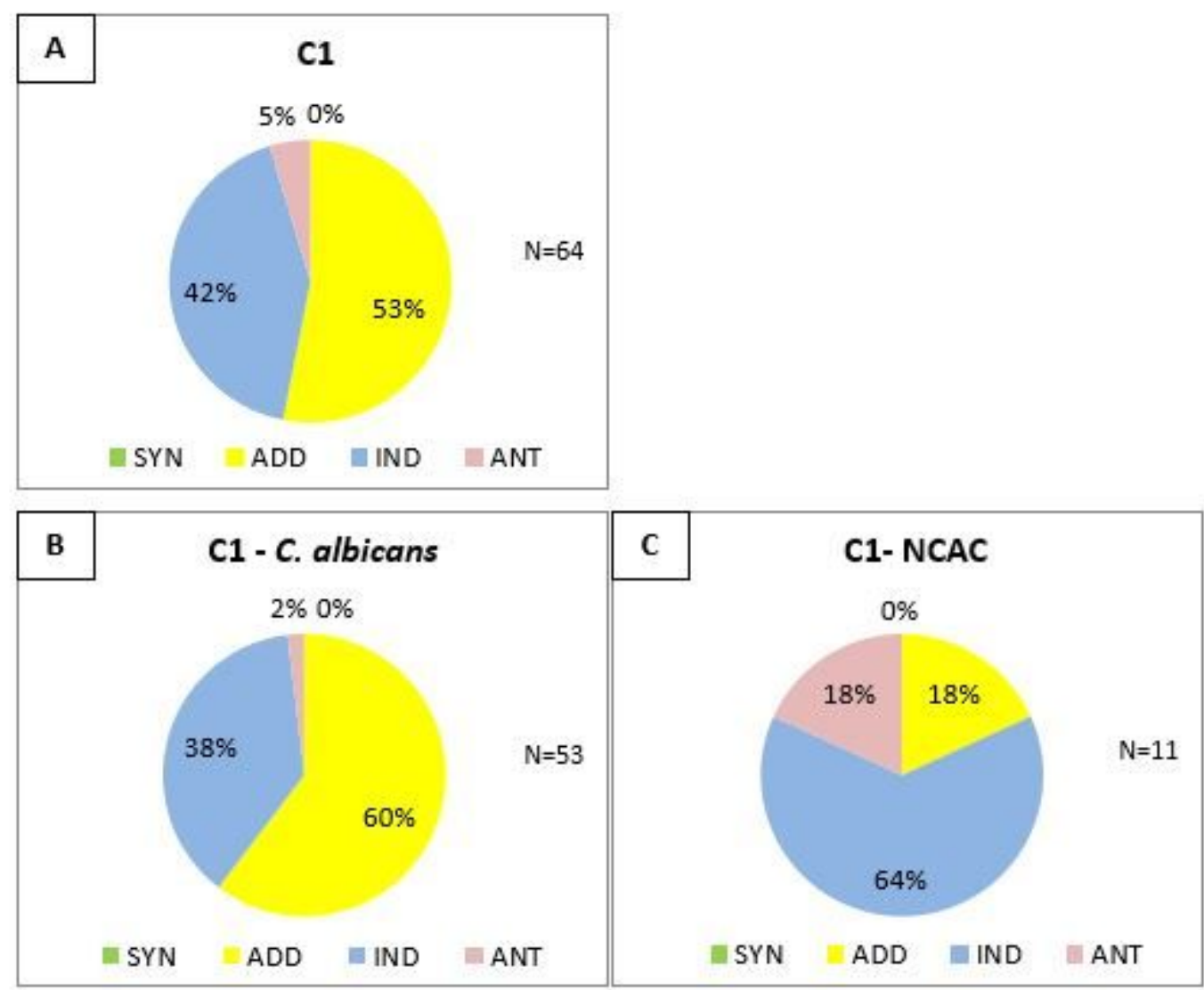

Figure 5

Distribution of FIC indices for the combination fluconazole-C2; (A) total - 64 strains; (B) C. albicans - 53 strains; (C) NCAC - 11 strains.

\section{Supplementary Files}

This is a list of supplementary files associated with this preprint. Click to download.

- SupplementarydataCzechowicz.docx

- formula.docx 